\title{
Diet for Diabetics and their Limitations
}

\section{Jeevani T}

Department of Biotechnology, Acharya Nagarjuna University, India

\begin{abstract}
Diabetes affects different people in different ways depending on their degree of diabetic complication. Diabetes is the leading cause of premature deaths. Diabetes is a disorder in which the body does not use the sugars in food in the usual way. Diabetics produce too little insulin or none at all, or cannot use insulin properly. Type I diabetes always requires insulin, diet, and exercise. Insulin or oral hypoglycemic agents are only prescribed for Type II diabetics. Whatever type of diabetes it may be the key to proper control is balancing the glucose and the insulin in the blood. Good management of diabetes needs healthy food intake and also fitness.
\end{abstract}

Keywords: Diabetes mellitus; Glucose; Insulin; Hyperglycemia; Hypoglycemia; Insulin resistance; carbohydrates; Antihyperglycemic effect; Antioxidant

Abbreviations: IDDM: Insulin Dependent Diabetes Mellitus; NIDDM: Non-Insulin Dependent Diabetes Mellitus; AGEs: Advanced Glycation End products

\section{Introduction}

The word 'diabetes' is a Greek word meaning 'flowing through'. The commonest form is called diabetes mellitus, or 'sweet flowing through', because glucose appears in urine [1]. The increased amount of urea excreted in the disease called polyuria [2]. Diabetes mellitus is an uncontagious chronic disorder of carbohydrate metabolism [3]. Normally, some of the food one digests is changed into glucose (sugar), which the body uses for fuel. Blood carries glucose to the cells where a hormone called insulin allows it to enter the cells. This high blood glucose leads to the conditions like weakness, hunger, poor growth, itchy skin, slow healing, drowsiness, overweight, blurred vision. Diabetics produce too little insulin or none at all, or cannot use insulin properly. Then dangerously high levels of glucose can build up in the blood. This is due to a malfunction of the hormone insulin which is produced in the beta cells of the pancreas. Insulin is a hormone that helps to regulate blood sugar levels by taking excess glucose out of the bloodstream and putting it into body cells to be used as fuel or to store as glycogen and fat. An accumulation of sugar in the blood leads to a build up in the blood called hyperglycaemia and then it appears in the urine. Symptoms include thirst, excessive production of urine and weight loss [4]. In people with diabetes, either the pancreas doesn't make sufficient insulin or the body is unable to use insulin properly. For either reason diabetes is characterised by raised levels of sugar in the bloodstream as blood glucose is not controlled. This can ultimately lead to diverse problems including blindness, gangrene, kidney disease, nerve damage and impotence. Although diabetes cannot be cured, it can be controlled. Individuals with diabetes mellitus fall into two broad groups i.e. type-1 and type-2 [5]. Those who have a deficiency of insulin are considered as (type-1) and those with a diminished effectiveness are considered as insulin (type-2) [6].

\section{Type 1 Diabetes}

Type-1 is where the cells producing insulin are damaged, so that there is a lack of insulin. Type 1 diabetes affects young people, commonly around the ages of 10 or 12 , it can also occur as early as one year and as late as forty [7]. The disease tends to develop rapidly and is severe. In this form of the disease, the beta cells of the pancreas do not produce sufficient insulin. This type of diabetes is called either type 1 diabetes or, more technically, insulin dependent diabetes mellitus (IDDM). Two kinds of problems occurs when the body doesn't make insulin Hyperglycemia and Hypoglycemia. Hyperglycemia occurs when blood glucose levels get too high [8]. This can occur when the body gets too little insulin or too much glucose in the bloodstream. Untreated, hyperglycemia may develop into ketoacidosis, a very serious condition. Treatment is invariably with insulin injections to make up the shortfall and reduce blood glucose levels. Hypoglycemia is the exact opposite of hyperglycemia. This occurs when blood glucose levels get too low, when the body gets too much insulin or too little food. Hypoglycemia is the most common problem in children with diabetes. Usually it is mild and is easily treated by giving the child a sweet food. But if not treated, it can be fatal.

\section{Type 2 Diabetes}

The second type of diabetes is much more common. It is also called type- 2 diabetes $[9,10]$. This occurs in middle-aged people, especially if they are overweight [11]. Because it occurs later in life, this type of diabetes is often called adult-or maturity-onset diabetes [12]. Type-2 diabetes is quite different from Type- 1 in that the pancreas does produce insulin often more than in a healthy person but there is resistance to its effects. It is a situation called insulin resistance. As Type- 2 is usually treated without the use of insulin, it is known technically as non-insulin dependent diabetes mellitus or NIDDM [13]. NIDDM is somewhat more common in pregnant women and those who have had several children [14]. It is also more common in men and women who are obese [15]. And, in the same way that type 1 diabetes is not found in the animal kingdom or in primitive man, neither is type 2 [16]. This form of the disease is a result of environmental and lifestyle factors is demonstrated when people emigrate and adopt the eating habits of their new country populations who migrate to westernized countries

${ }^{*}$ Corresponding authors: Jeevani T, Department of Biotechnology, Acharya Nagarjuna University, Guntur, India, E-mail: jeevanithota@yahoo.co.in

Received November 13, 2011; Accepted December 21, 2011; Published December 26, 2011

Citation: Jeevani T (2011) Diet for Diabetics and their Limitations. J Diabetes Metab 2:168. doi:10.4172/2155-6156.1000168

Copyright: (c) 2011 Jeevani T. This is an open-access article distributed unde the terms of the Creative Commons Attribution License, which permits unrestricted use, distribution, and reproduction in any medium, provided the original author and source are credited. 
with more sedentary lifestyles have greater risks of type 2 diabetes than their counterparts who remain in their native countries $[17,18]$.

\section{Insulin}

In type 1 diabetes, the pancreas doesn't produce enough insulin [19]. That is not the case with type 2 diabetes, here the pancreas does produce insulin but that insulin is ineffective. It is a situation called insulin resistance [20]. Insulin is a hormone, produced in the beta cells of the pancreas [21]. It carries glucose (blood sugar) from blood into body's cells so that it can be burned for energy or stored as glycogen or fat for future use. Insulin resistance and its role in diabetes is a controversial topic. The original concept of insulin resistance referred to the clinical observation that some patients with diabetes required very large doses of insulin to lower their blood sugars. Individuals with Type 2 diabetes had high insulin levels and they introduced the concept of insulin resistance [22]. The insulin receptor is usually not the cause of insulin resistance. Insulin resistance is also considered a risk factor for heart disease [23].

\section{Diabetic Food}

Eating right is vital if one trying to prevent or control diabetes [24]. While exercise is also important but what an individual eats is more important for weight loss [25]. A diabetes diet is simply a healthy eating plan that is high in nutrients, low in fat, and moderate in calories [26]. It is a healthy diet for anyone [27]. The only difference is that one needs to pay more attention to some of food choices most notably the carbohydrates [28]. Excessive fat, sucrose (sugar) and other carbohydrates, and inadequate dietary fibre are primarly important. The causes of diabetes have not been clearly identified. Various studies pointed out the correlation between carbohydrate intake and diabetes and referred as diabetes is caused by an excessive intake of carbohydrates just as obesity is $[29,30]$. Prevention and controlling diabetes doesn't mean living in deprivation. Its eating right and any individual can still enjoy their favorite food. One shouldn't have to give up sweets entirely or resign to a lifetime of healthy food and carbohydrate counting. But one should probably need to learn some better eating habits. The most important thing is to lose weight and one doesn't have to lose all the extra pounds to reap the benefits. Experts say that losing just 5\% to $10 \%$ of one's total weight can help them lower blood sugar as well as lower blood pressure and cholesterol [31,32]. Increased endogenous generation of advanced glycation end products (AGEs) contributes importantly to the vascular complications of diabetes. Low-fat carbohydrate-rich foods tend to be relatively low in AGEs [33].

\section{Carbohydrates}

Diabetics may be encouraged to reduce their intake of carbohydrates that have a high glycemic index [34]. Carbohydrates have a big impact on blood sugar levels more than fats and proteins but avoid them. In general, it's best to limit highly refined carbohydrates like white bread, pasta, and rice, as well as soda, candy, and snack foods [35]. Focus instead on high-fiber complex carbohydrates also known as slow-release carbs [36]. Slow-release carbs help keep blood sugar levels even because they are digested more slowly, thus preventing body from producing too much insulin. They also provide lasting energy and help you stay full longer. Different amounts of carbs may be eaten for this reason, the types of foods to eat and to avoid is the same for all. Low-carbohydrate diets in obese patients with type 2 diabetes seem attractive due to their antihyperglycemic effect $[37,38]$. Carbohydrate diet with some caloric restriction to obese patients with type 2 diabetes has lasting effects on bodyweight and glycemic control [39].

\section{Starch}

Starches are bread, grains, cereal, pasta, and starchy vegetables like corn and potatoes [40]. They provide carbohydrate, vitamins, minerals, and fiber [41]. Whole grain starches are healthier because they have more vitamins, minerals, and fiber. Starches are must at each meal Eating starches is healthy for everyone, including people with diabetes. Starches include bread, potatoes, corn, rice, beans, cereals, lentils, yams etc.

\section{Vegetables}

Based on the components of plant-based diets and their effects from cohort studies, there is belief that vegetarian diets would have advantages in the treatment of type 2 diabetes [42]. Vegetables provide vitamins, minerals, and fiber. They are low in carbohydrate. Vegetables include lettuce, spinach, peppers, carrots, chilies, cabbage, green beans, vegetable juices, broccoli etc.

\section{Fruits}

Fruits provide carbohydrate, vitamins, minerals, and fiber. Apples, Avocados, Figs, pomegranates, grapes and citrus fruits can be consumed [43]. Eat fruits raw or as juice with no sugar added, canned in their own juice, or dried. Eat smaller pieces of fruit. Whole fruit is more filling and has more fiber. Save high-sugar and high-fat fruit desserts such as peach cobbler or cherry pie for special occasions.

\section{Meat and Meat Substitutes and Milk}

The meat and meat substitutes group includes meat, poultry, eggs, cheese, fish, and tofu. Eat small amounts of some of these foods each day. Meat and meat substitutes provide protein, vitamins, and minerals. Chicken, eggs, cheese beef can be consumed. Chicken or turkey without the skin can be consumed, cooking meat in low-fat ways is best. Limit the amount of nuts, peanut butter, and fried foods you eat. They are high in fat. Drink fat-free (skim) or low-fat (1\%) milk [44]. Low-fat or fatfree fruit yogurt sweetened with a low-calorie sweetener is suggested. Instead use low-fat plain yogurt as a substitute for sour cream.

\section{Fats and Sweets}

Limit the amount of fats and sweets. Fats and sweets are not as nutritious as other foods. Fats have a lot of calories [45]. Sweets can be high in carbohydrate and fat. Some contain saturated fats, trans-fats, and cholesterol that increase your risk of heart disease [46]. Limiting these foods will help to lose weight and keep blood glucose and blood fats under control. Butter, olives, oil, cream cheese, cakes, ice cream, cookies, syrups etc constitute unsafe for diabetic patients.

\section{Alcoholic Drinks}

Alcoholic drinks have calories but no nutrients [47]. If alcoholic drinks are consumed on an empty stomach, they can make blood glucose levels go too low [48]. Alcoholic drinks also can raise blood fats $[32,49]$.

\section{Foods to be Avoided}

Sugar is a problem as it is addictive so sugar and artificial sweeteners, including honey can be suggested to cut down gradually. The other option is to stop it altogether. This will give withdrawal symptoms, just like stopping any other addictive drug. Sweets and chocolates including so-called sugar-free types should be avoided. "Diet" and "sugar-free" foods except sugar-free jelly should be avoided. Salt is the 
greatest culprit for diabetics. Enough salt is obtained from vegetables in inorganic form, so reduce the intake of inorganic salt. Excessive fat intake is definitely not a good habit. Exclude fried items from diet totally. But a small quantity of oil to absorb fat-soluble vitamins, especially vitamin E can be consumed. Grains and foods made from wheat, rye, barley, corn, rice, bread, pasta, pastry, cakes, biscuits, pies, tarts, breakfast cereals. Starchy vegetables like potatoes and parsnips in particular should be minimized. Beans with the exception of runner beans can be suggestible. Milk can be taken in small quantities, Sweetened, fruit and low-fat yogurts, Cottage cheese in small amounts. Switch to low fat milk and its products like yogurt (curd). Replace high fat cheese with low fat cottage cheese [50]. Do not have than two cups of the conventional tea or decaffeinated coffee every day [51]. Beware of commercially packaged foods fast foods, snack foods and health foods and finally fruit juices, as these are much higher in carbs than fresh fruit $[52,53]$.

\section{Special Food for Diabetics}

Bitter gourd contains a high dosage of 'plant insulin'. It lowers the blood-sugar levels effectively and it can be taken on a regular basis. Fenugreek is the most common food used to control diabetes. Gulp a teaspoonful of these seeds with a glass of water daily. Overnight soaked seeds can be drained and the water can be taken. Indian blackberry is very effective in preventing and controlling diabetes. It contains glucoside, which prevents the conversion of starch into sugars. Garlic is used to lower blood-sugar levels. It is rich in potassium and replaces the potassium which gets lost in urine. It also contains zinc and sulphur, which are components of insulin. Raw onion is more useful because of its diuretic and digestive properties, onion works against diabetes. Flaxseed is the richest source of Omega 3 fatty acids [54]. It helps control diabetes because it maintains the sensitivity of the cell membrane, facilitates insulin, and thereby the uptake of glucose by the cells. Soluble fibers found in apples, kidney beans, oatmeal, soyabean, etc, help control diabetes. These aid slow digestion and absorption of nutrients, resulting in a slow and steady release of glucose. They soak up excess bile acids found in the intestinal tract, the same acids that are converted to blood cholesterol [55]. They also help empty the stomach and trigger satiety that can help Type 2 diabetics to achieve weight loss goals. Water extracts of cinnamon have been found to promote glucose metabolism and reduce cholesterol. Diabetes is often associated with conditions like heart disease, diabetic retinopathy, immune deficiency and kidney disease. Antioxidants [56], especially vitamin C (lemons), $\mathrm{E}$, selenium, zinc and chromium (Brewer's yeast) can be consumed as they have been shown to control blood sugar levels [57,58].

\section{Conclusion}

There is no cure for diabetes. However, one can manage or delay diabetes through diet, exercise, weight control and, if necessary, medication. Eating a variety of foods, maintaining a healthy weight, choosing a diet low in fat, saturated fat, and cholesterol, increasing intake of fiber foods, controlling sugar consumption, using salt (sodium) only in moderation, moderate alcohol consumption are certain precautions taken for the diabetic control.

\section{References}

1. Li YW, Aronow WS (2011) Diabetes Mellitus and Cardiovascular Disease. J Clinic Experiment Cardiol 2: 114.

2. Vestergaard $P$ (2011) Diabetes and Bone. J Diabetes Metab S: 1.

3. Ramanathan K, Karthick H, Arun N (2010) Structure Based Drug Designing for Diabetes Mellitus. J Proteomics Bioinform 3: 310-313.
4. Kablan A, Saunders RA, Szkudlarek-Mikho M, Chin JB, Bosio RM, et al. (2010) Prieurianin Causes Weight Loss in Diet-Induced Obese Mice and Inhibits Adipogenesis in Cultured Preadipocytes. J Diabetes Metab 1: 101.

5. Belmokhtar F, Belmokhtar R, Charef M (2011) Risk Factors Associated With Type 2 Diabetes Mellitus in West Region of Algeria, Maghnia. J Diabetes Metab 2: 148.

6. Fouqueray P, Leverve X, Fontaine E, Baquié M, Wollheim C, et al. (2011) Imeglimin - A New Oral Anti-Diabetic that Targets the Three Key Defects of type 2 Diabetes. J Diabetes Metab 2: 126.

7. Turconi G (2011) Healthy Aging: Nutritional Intervention to Improve and Extend Quality of Life among Older People. J Nutr Food Sci 1: e101.

8. http://www.sciencedaily.com/articles/h/hyperglycemia.htm

9. Esteghamati A, Nakhjavani M, Aminorroaya A, Aboutorabi R, M Niafar, et al. (2011) Biphasic Insulin Aspart 30 (BIAsp 30) is Safe and Improves Glycaemic Control in Insulin Naïve Patients with Type 2 Diabetes. J Diabetes Metab 2 : 123.

10. Kumar R, Kumar AN, Ahmed S (2011) Changes in Erythrocyte Membrane in Type-2 Diabetes Mellitus with and without Dyslipidemia. J Diabetes Metab 2 141

11. Silvola JM, Saraste A, Laitinen I, Savisto N, Laine VJ, et al. (2011) Effects of Age, Diet, and Type 2 Diabetes on the Development and FDG Uptake of Atherosclerotic Plaques. JACC Cardiovasc Imaging 4: 1294-301.

12. Tan AM, Muthusamy L, Ng CC, Phoon KY, Ow JH, et al. (2011) Initiation of insulin for type 2 diabetes mellitus patients: what are the issues? A qualitative study. Singapore Med J 52: 801-809.

13. Kamoi K, Ohara N, Tomoo I, Shinozaki Y, Furukawa K (2011) Normal Response of Active GLP-1 like Substances Level to Test Meal in Non-Obese Type 2 Diabetic Japanese Patients with Complications and Receiving Treatments. J Diabetes Metab 2: 147.

14. Ramos-Jiménez A, Hernández-Torres RP, Wall-Medrano A (2011) Hatha Yoga Program Determinants on Cardiovascular Health in Physically Active Adult Women. J Yoga Phys Therapy 1: 103.

15. Takasaki S (2011) Mitochondrial Haplogroups Associated with Japanese Centenarians, Alzheimer's Patients, Parkinson's Patients, Type 2 Diabetes Patients, Healthy Non-Obese Young Males, and Obese Young Males . J Proteomics Bioinform 4: 106-112.

16. Abougalambou SSI, Hassali MA, Sulaiman SAS, Abougalambou AS (2011) Prevalence of Vascular Complications among Type 2 Diabetes Mellitus Outpatients at Teaching Hospital in Malaysia. J Diabetes Metab 2: 115.

17. Manson JE, Spelsberg A (1994) Primary prevention of non-insulin-dependent diabetes mellitus. Am J Prev Med 10: 172-184

18. Samadi N, Safavi M, Mahmoodi M (2011) Impact of Quality of Life Education on Self-Concept among Type 2 Diabetes Patients. J Diabetes Metab 2: 132.

19. Uppu RM, Parinandi NL (2011) Insulin Sensitization and Resistance Interrelationship Revisited with a Quantitative Molecular Model Approach. J Diabetes Metab 2: 106e.

20. Ragheb R, Medhat AM (2011) Mechanisms of Fatty Acid-Induced Insulin Resistance in Muscle and Liver. J Diabetes Metab 2: 127.

21. Ramachandra S (2011) Do we need yet another Insulin? J Diabet Metabol 2 0e4

22. Himsworth HP (2011) Diabetes mellitus: its differentiation into insulin-sensitive and insulin-insensitive types. Diabet Med 28: 1440-1444.

23. Krook A, O Rahilly S (1996) Mutant insulin receptors in syndromes of insulin resistance. Bailliers Clin Endocrinol Metab 10: 97-122.

24. Kaneko M, Suzuki H, Watanabe H, Oda E, Aizawa Y (2011) Metabolic Syndrome is a Poor Predictor of Incident Diabetes Compared with Hemoglobin A1c (Hba1c) in a General Japanese Population. J Diabetes Metab S: 2.

25. Mungrue K, Roper LA, Chung T (2011) Assessment of Weight Loss in the Management of Patients with Type 2 Diabetes Mellitus in Primary Care in Trinidad. J Diabetes Metab 2: 120.

26. Shanker JH, Mahmood SE, Joshi MC, Shaifali I (2011) Obesity Indices amongs Diabetics in an Urban Population of Western Nepal. J Diabetes Metab 2: 134. 
27. Ali ZH (2011) Health and Knowledge Progress among Diabetic Patients after Implementation of a Nursing Care Program Based on Their Profile. J Diabetes Metab 2: 121.

28. Huffman FG, Vaccaro JA, Nusrath NS, Zarini GG (2011) The Effect of Carbohydrate Amount, Quality and Type on Arterial Pulse Pressure in CubanAmericans with and Without Type 2 Diabetes. J Nutr Food Sci 1: 106.

29. Horita S, Seki G, Yamada H, Suzuki M, Koike K, et al. (2011) Insulin resistance obesity, hypertension, and renal sodium transport. Int J Hypertens 391762.

30. Gayes JM (2011) Obesity, Obstructive Sleep Apnea and the "HELP" Position. J Anesthe Clinic Res 2: 115.

31. Nakagami T, Yamamoto Y, Fukushima S, Oya J, Iwamoto Y, et al. (2011) Assessment of Cholesterol Absorption and Synthesis in Japanese Patients with Type-2 Diabetes and Lipid-Lowering Effect of Ezetimibe. J Diabetes Metab 2. 139

32. Míguez MJ, Rosenberg R, Burbano X, Malow R (2011) Cholesterol as a Mediator of Alcohol-Induced Risks for Respiratory Disease Hospitalizations among People Living With HIV. J AIDS Clinic Res S1: 001.

33. McCarty MF (2005) The low-AGE content of low-fat vegan diets could benefit diabetics - though concurrent taurine supplementation may be needed to minimize endogenous AGE production. Med Hypotheses 64: 394-398.

34. http://www.drmcdougall.com/misc/2006nl/july/pdf060700gi.pdf

35. Aberoumand A (2011) Protein, Fat, Calories, Minerals, Phytic acid and Phenolic In Some Plant Foods Based Diet. J Food Process Technol 2: 114.

36. Garg A, Bantle JP, Henry RR, Coulston AM, Griver KA, et al. (1994) Effects of varying carbohydrate content of diet in patients with non-insulin-dependent diabetes mellitus. JAMA 271: 1421-1428.

37. Jakubowicz D, Froy O, Wainstein J, Boaz M (2011) Meal timing and composition influence ghrelin levels, appetite scores and weight loss maintenance in overweight and obese adults. Steroids.

38. Nichol A, Chandra Sekar M (2011) Successful Management of Extremely Insulin-Resistant Obese Diabetic Patient with Insulin Glargine, U-500 Regular Insulin and Pramlintide. J Diabetes Metab 2: 143.

39. Nielsen JV, Joensson E (2006) Low-carbohydrate diet in type 2 diabetes Stable improvement of bodyweight and glycemic control during 22 months follow-up. Nutr Metab (Lond) 3: 22.

40. Thao HM, Noomhorm A (2011) Physiochemical Properties of Sweet Potato and Mung Bean Starch and Their Blends for Noodle Production. J Food Process Technol 2: 105.

41. Nagendra Prasad MN, Sanjay KR, Shravya Khatokar M, Vismaya MN Nanjunda Swamy S (2011) Health Benefits of Rice Bran - A Review. J Nutr Food Sci 1: 108

42. Jenkins DJ, Kendall CW, Marchie A, Jenkins AL, Augustin LS, et al. (2003) Type 2 diabetes and the vegetarian diet. Am J Clin Nutr 78: 610-616.

43. Mansouri YS, Khazaei J, Hassan Beygi SR, Mohtasebi SS (2010) Statistica Modeling of Pomegranate (Punica granatum L.) Fruit with Some Physical Attributes. J Food Process Technol 1: 102
44. Munsch-Alatossava P, Gursoy O, Alatossava T (2010) Improved Storage of Cold Raw Milk by Continuous Flushing of N2 Gas Separated from Compressed Air: A Pilot Scale Study. J Food Process Technol 1: 10.

45. Mrudula T, Ghafoorunissa, Saravanan N, Reddy GB (2011) Effects of Prenata and Postnatal Dietary Polyunsaturated Fatty Acids on Retinal Fatty Acid Composition and Gene Expression in Adult Rat. J Nutr Food Sci 1: 102

46. Rivera-Ramírez F, Escalona-Cardoso GN, Garduño-Siciliano L, Galaviz Hernández C, Paniagua-Castro N (2011) Antiobesity and Hypoglycaemic Effects of Aqueous Extract of Ibervillea sonorae in Mice Fed a High-Fat Diet with Fructose. J Biomed Biotechnol.

47. McCarty MF (2005) The low-AGE content of low-fat vegan diets could benefit diabetics - though concurrent taurine supplementation may be needed to minimize endogenous AGE production. Med Hypotheses 64: 394-398.

48. Li H, Wang G, Wang A, Tong W, Zhang Y (2011) Alcohol Consumption and Risk of Type 2 Diabetes in Mongolian Population, Inner Mongolia, China. J Diabetes Metab 2: 116.

49. Khosravi S, Alavian SM, Zare A, Daryani NE, Fereshtehnejad SM, et al. (2011) Non-alcoholic fatty liver disease and correlation of serum alanin aminotransferase level with histopathologic findings. Hepat Mon 11: 452-458.

50. Mooney RA, Sampson ER, Lerea J, Rosier RN, Zuscik MJ (2011) High fat diet accelerates progression of osteoarthritis following meniscal/ligamentous injury. Arthritis Res Ther 13: 198.

51. Matsuda Y, Kobayashi M, Yamauchi R, Ojika M, Hiramitsu M, et al. (2011) Coffee and Caffeine Improve Insulin Sensitivity and Glucose Tolerance in C57BL/6J Mice Fed a High-Fat Diet. Biosci Biotechnol Biochem.

52. Nikoo M, Ghomi MR, Rahimabadi EZ, Benjakul S, Javadian B (2010) The Effects of Deep-Frying, Refrigerated Storage and Reheating on the Fat Content, Oxidation and Fatty Acid Composition of the Fish Rutilus frisii kutum. J Food Process Technol 1: 103

53. Khan MA, Semwal AD, Sharma GK, Mahesh C, Nataraj S, et al. (2011) Development and Evaluation of Long Shelf-Life Ambient Stable Chapaties Without The Use of Chemical Preservatives. J Food Process Technol 2: 107.

54. Dhibi M, Brahmi F, Mnari A, Houas Z, Chargui I, et al. (2011) The intake of high fat diet with different trans fatty acid levels differentially induces oxidative stress and non alcoholic fatty liver disease (NAFLD) in rats. Nutr Metab 8: 65.

55. Calle MC, Vega-López S, Segura-Pérez S, Volek JS, Pérez-Escamilla R, et al (2010) Low Plasma Hdl Cholesterol and Elevated C Reactive Protein further Increase Cardiovascular Disease Risk in Latinos with Type 2 Diabetes. J Diabetes Metab 1: 109

56. da Silva SB, Costa JP, Pintado ME, Ferreira DC, Sarmento B (2010) Antioxidants in the Prevention and Treatment of Diabetic Retinopathy - A Review. J Diabetes Metab 1: 111

57. Tsai SJ, Huang CS, Mong MC, Kam WY, Huang HY, et al. (2011) Antiinflammatory and Antifibrotic Effects of Naringenin in Diabetic Mice. J Agric Food Chem.

58. Turconi G, Simonetti P, Brusamolino A, Rondanelli M, Roggi C, et al. (2011) Nutritional and Plasma Antioxidant Status Assessment in a Group of Old Alzheimer's Inpatients. J Nutr Food Sci 1: 101 